\title{
Moth-Flies that Cause Myiasis in Man in Japan
}

\author{
By
}

\section{Masaaki Tokunaga}

The purpose of this paper is to discuss the myiasis-producing moth-flies on the materials found from two Japanese patients.

I wish to express my hearty thanks to Prof. Dr. K. Morishita of Osaka University who kindly sent the valuable material to our laboratory to study freely. Prof. Dr. T. Esaki of Kyusyu University has most generously presented his Psychodid collection from Japan and England to my study. I wish to thank Dr. W. W. Wirth of Washington, Mr. S. Ito of Osaka Naniwa University and Dr. G. W. Byers of Michigan to their kind help sending their important collections for this study and also to thank Prof. Dr. K. Yasumatsu whose loan of the important literature. I appreciated the aid rendered to me by Mr. M. Sasakawa and Miss E. Komyo of our laboratory during the study of this problem.

\section{What species of the Paychodidae cause the human myiasis?}

Human myiasis caused by the Psychodid flies is rarely known not only in Japan but in other countries.

In 1927 Jo K. Okada reported a girl patient of seventeen years old who vomited larvae of Psychoda sexpunctata Curtis from Japan. W. S. Patton and A. M. Evans in 1929 described an urinary myiasis of a boy caused by Psychoda albipennis Zetterstedt in Scotland. In 1933 O. A. Johannsen described that larvae of Psychoda species B were sent to Dr. E. H. Hinman of New Orleans, Louisiana, by a physician who stated that they had been passed in the urine of a female patient. In $1941 \mathrm{I}$ observed living Psychodid larvae obtained from the urine and genital organ of a young girl patient of the hospital of Kyoto University and in $1943 \mathrm{I}$ reported this undetermined Psychoda species which causes urinary and genital myiasis of man in my Text-Book of Medical Entomology. In this case, at first, I have obtained two minute larvae which were found floating on the surface of the urine in vial by a physician. Then we have carefully examined on the patient and detected a similar larva in a fresh urine and another larvae in washings the genital organ. At the second regular meeting of Japanese Society of Medical Entomology, in 1950, K. Morishita reported of a case of intestinal myiasis, that many living larvae and pupae were excreted from a woman patient of 48 years old.

Myasis-producing diptera were grouped into three, from the view-point of the habbit of the flies by myself (1943): (1) eumyiasis group, (2) semimyiasis group, and (3) pseu- 
domyiasis group and R. Matheson (1950) also grouped them into three: (1) specific myiasisproducing flies, (2) semispecific, and ( 3 ) accidental. In the cases of known human myiasis caused by the Psychodidae, they fall within the third category because of the following systematic and ecological facts.

$P$ sychoda sexpunctata reported by Okada, although Johannsen questioned the synonymy, is now regarded as a synonym of $P$. alternata by A. E. Eaton (1894), H. G. Dyar (1926), F. del Rosario (1936), etc. Psychoda sp. B., according to D. T. Fullaway (1907), is thought to be identical with or closely related to $P$. schizura Kincaid. On the other hand, $P$. schizura is also said to be identical with $P$. alternata. Thus $P$. alternata, $P$. sexpunctata, $P$. schizura and $P$. sp. B. seem to be all synonymous to each other.

The Psychodid larvae obtained from a young girl at Kyoto were very small about $2 \mathrm{~mm}$ long and failed to be bred up to adult flies. But recently I have compared many Japanese specimens with those of North America and Europe, to identify the larvae which were found from a girl patient with the first instar larvae of $P$. alternata, although the development of the dorsal sclerities on the posterior abdominal segments of the larvae were somewhat different from those of exotic specimens. At the same time the commonest domestic moth-flies of Japan belong to this cosmopolitan species. Psychoda albipennis is a distinct species differing from alternata-like species.

Finally the larvae and pupae obtained from a women patient of Osaka by Morishita are quite different from the known myiasis-producing Psychoda species. I have compared these immature forms with those of various known species of the Psychodidae and found out that they are Telmatoscopus albipunctatus Willistone.

The above investigation from the systematic view-point leads to the conclusion that the known myiasis-producing moth-flies belong to following three species: Psychoda alternata Say (=sexpunctata Curtis =schizura Kincaid=sp. B. of Johannsen), P. albipennis Zetterstedt and Telmatoscopus albipunctatus Williston. Of these species, the first causes urinary, intestinal and genital myiasis, the second urinary myiasis and the third intestinal myiasis of man.

\section{How the moth-flies cause the human myiasis?}

All of these moth-flies are not habitually parasitic but they are all free living in normal state. The immature stages of $P$. alternata are found in the surface film of foul water, in sewages, in the filter beds of sewage disposal plants and decaying wet vegetables and other organic matter. The adult flies are very commonly found in the latrine and kitchen room and according to Johannsen they are frequently found breeding in the traps of washbowls in toilet rooms and to M. T. James (1947) they are capable of developing in water pipes. I have also observed they are breeding together with Chironomid larvae in a hydorant of water supply which was dropping water. This is very suggestive for route of infection of intestinal myiasis.

Related to $P$. albipennis, James reported that the larvae are found in moist places, 
such as ditches, decaying moist vegetable matter, decaying fruit, the sides of drains, and in filter beds of sewage-disposal plants, where they may occur very abundantly on the bacterial film. Thus this moth-flies are also very similar in habitat to $P$. alternata.

Telmatoscopus albipunctatus is another myiasis-producing Psychodid species in Japan. This species are widely distributed in tropical regions, yet it is a new arrival here. In Japan, it is known from Fukuoka and Osaka, but very rare in Kyoto and quite unkown in northern regions from Kyoto. This fly breeds in sewages and sinks in Japan. In the Hawaiian Islands, F. X. Williams (1946) showed that it breeds in sinks, drains, tree holes, rain barrels, shallow little pools, very wet mud of forest and in lavatories. Thus the breeding place of $T$. albipunctatus is very similar to those of $P$. alternata.

The process of infection of these myiasis is not proved as yet so far as I know, but in the case of intestinal myiasis the infection seems possible from eating and drinking fould vegetable and water or taking rotten fruit containing young larvae and eggs or from using fouled teacups and rice-bowles on which the eggs are deposited. In the case of $P$. alternata, there is more probable to drink the larvae together with unboiled water directly from a hydrant of water supply in which if they are breeding as I have observed. Almost always, being dark, wet and moistened the kitchen room of the Japanese house is suitable for the life of moth-flies and moreover this room is provided with a waterpot or pail which may offer a suitable breeding place to the flies. Thus the accidental chance to take eggs or larvae of these flies via mouth seems to be not rare in Japan. In the case of $T$. albipunctatus, the excreted larvae with the dejecta were all in the full grown stage and the pupae were in various stages before the emergence. Thus it is almost impossible to suppose that the woman has drunk carelessly these rather large insects of considerable number. It is rather probable that these insects were taken via mouth in their early stage and successively had developed to attain these later advanced stages in the intestine.

The route of infection of the urogenital myiasis caused by the Psychodid flies is not clear. Patton and Evans, in the case of urinary myiasis of a young boy, conjectured invasion through eating of infested soil and passage of the larvae from the rectum to the bladder. I intend to propose another conjecture in the cas of female patients. In the rural house, the flies freely enter into the lavatory which is not built tightly and toilet papers or clothes which are customarily provided in this room may be often contaminated by the flies" when these are moistened or wet. Using these papers or clothes, the eggs or young larvae are transmitted to urinary or genital organs and then the larvae gain entrance. Similar infection may be conjectured in the case of fouled or wet swarthing clothes and underwares of female children which are contaminated by the oviposition of the flies. In the case of $P$. alternata observed by myself in 1941, the larvae were all very young suggesting that they have gained entrance directly along the routs discussed above and not seem to have passed so long time after the hatching that they have Imigrated into the urogenital organs from the intestine. 


\section{Psychoda alternata Say}

This moth-fly is widely distributed on the world and, according to del Rosario (1936), following eleven species are all synonymous to the present species: ITipula |phalaenoides var. Scope, Trichoptera phalaenoides Meig., Psychoda sexpunctata Curtis, P. marginepunctata Roser, $P$. schizura Kincaid, $P$. floridica Haseman, $P$. nocturala Haseman, $P$. bengalensis Brunetti, P. albimaculata Welch and P. dakotensis Dyar.

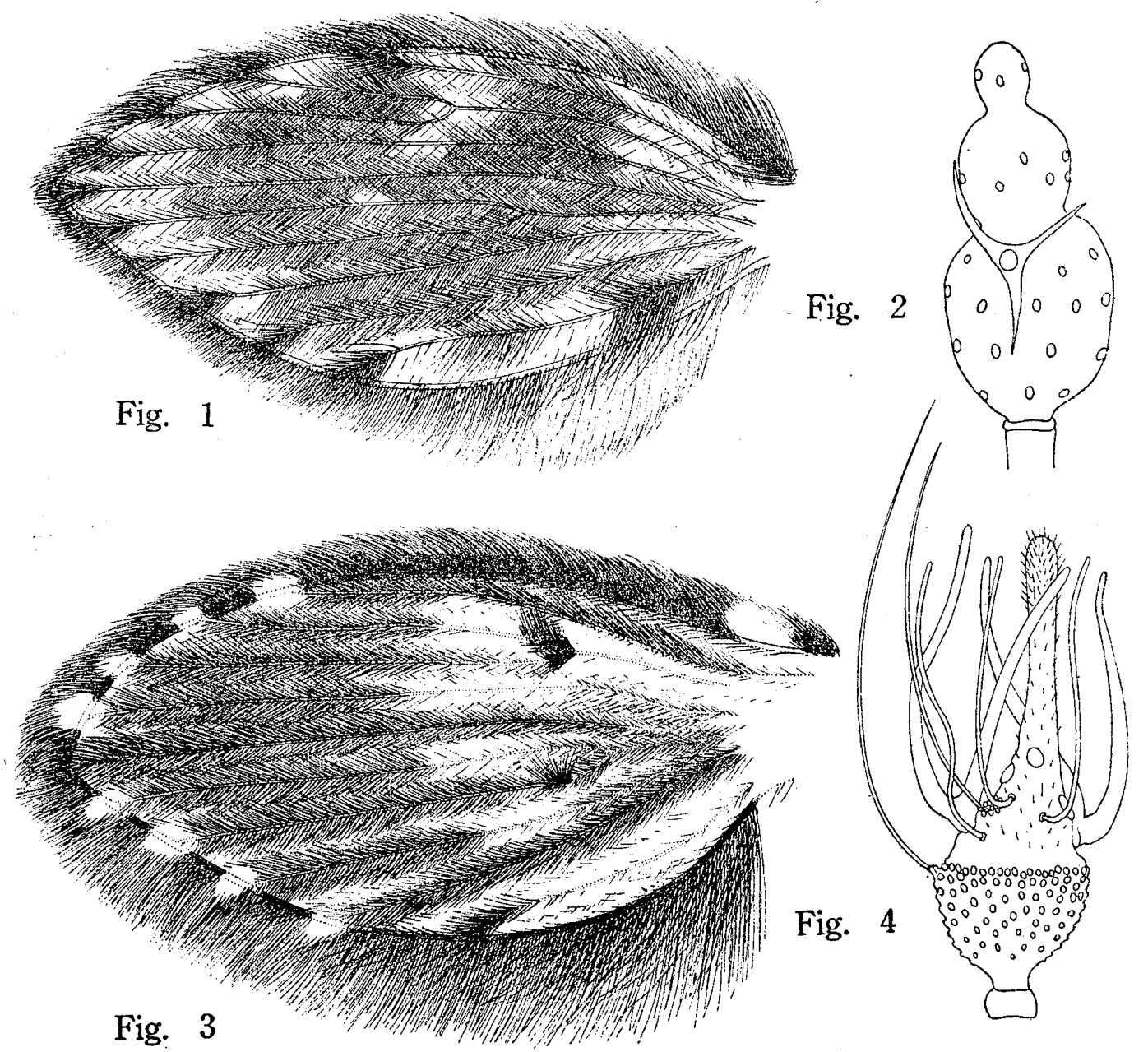

Psychoda alternata Say: Fig. 1, female wing. Fig. 2, distal end of male antenna. Telmatoscopus albipunctatus Williston: Fig. 3, female wing. Fig. 4, ultimate seg. ment of male antenna.

This species is very abundant every.where in Japan and thighly specific in the colouration of the wings (Fig. 1) which are provided with alternate white and black spots along the margin showing a mottled appearance. There is not known in Japan, as yet, other Psychoda species shows similar appearance of ithe wings. Other specific characters of the adult and immature stages are as follows:

Adult : - Body length about $1.8-2 \mathrm{~mm}$ in female and $1.3-1.5 \mathrm{~mm}$ in male. Antennae (Fig. 2) 15-segmented, but ultimate three subconfluent with each other forming la nodulous 
segment; each flagellar and nodulous segment with a pair or small Y-shaped sensory organs. Male hypopygium with a pair of slender ventral claspers, each of which bears a minute spoon-like spine at tip. Female subgenital plate very large and V-shaped.

Pupa :- Body yellowish or pale brown, about 4-6 mm long, without distinct setae, but with coarse spinules on abdominal segments. Respiratory horns long, cylindrical, about three-quarters as long as sheath of fore leg, with a double row of spiracular opennings.

Larva : - In full grown stage, body length about $6-8 \mathrm{~mm}$, body setae few and delicate, general colouration grayish white, but head and caudal respiratory tube dark brown, sixth and seventh abdominal segments each with three dorsal plates; caudal respiratory tube slender and taper.

The colouration of the adult is often variable; in the paler specimens, the wing is provided with only six small dark spots along the margin at the ends of veins $R_{1}, R_{2}, R_{4}$, $M_{1}, M_{3}$ and $\mathrm{Cu}_{1}$, and other dark markings are very much obscure showing a pale gray appearance. In the dark specimens the wing is provided with nine large and four small dark spots along the margin, and other indistinct clouds on the membrane are also darker. Concerning the antennae, all Japanese specimens are provided with small but slender $\mathrm{Y}$ shaped sensory organs differing from some of American specimens, in which these organs are smaller and somewhat star-shaped with three arms. In this point European specimens are more related to American than Japanese. The female subgenital plate is highly characterlistic for this species, but the detail of its structure somewhat variable: in some specimens the distal ends of the arms are truncated, in other pointed, and in many cases obtuse.

In the case of the pupa, the thoracic respiratory horn varies its relative length to. the sheath of fore leg from three-fourths of to subequal to the sheath, and the shape of the horn is cylindrical in major cases but in sometimes clubated apically or slightly constricted beyond the middle. The number of sternal spinules of the abdominal segments beyond the tips of the wing sheaths, except for the caudal marginal rows of spinules, varies from two to four.

In the majority of Japanese larvae, the development of the dorsal sclerites is very slight, and only the sixth and seventh abdominal segment are provided with three plates respectively, but in early larval stapes, especially in the first larval stage, one or two and rarely three dorsal sclerites are found on the fifth abdominal segment. The thoracic segments are usually devoid of dorsal sclerites, but in the first larval stage the prothoracic segment often bears a dorsal plate and rarely meso- and metathoracic segment are provided with similar plates. The posterior lateral double setae are almost always present on the abdominal segments, but their basal minute common plates not distinctly develop in the later stages and they are only present in some individuals of the first larval stage.

In 1951 I have shown a larva and pupa of Psychoda sp. with figures, and at present I intend to report that this species belongs to Psychoda alternata. 


\section{Telmatoscopus albipunctatus Williston}

This moth-fly is widely distributed in tropical regions and sometimes known from the northern region and the following species names are all synonymous to the present species: Telmatoscopus meridionalis Eaton, Psychoda snowii Haseman and P. erecta Curran.

This species is black and provided with white distinct spots on the legs and wings and one of the largest Japanese moth-flies. The main specific characters of the species are as follows :

Adult:- Body length about 4-5 mm. Antennae 16-segmented, very long, cach flagellar segment (Fig. 4) with an elongate distal part, many filiform sensory hairs and a pair gf large sensory organs; in male these sensory organ bifid and in female simple. Wing (Fig. 3) dark, with eight white spots along margin at ends of $R_{1}, R_{2}, R_{3}, R_{4}, M_{3}, M_{2}, M_{3+4}$, and $\mathrm{Cu}_{1}$ and other six white spots before the middle of wing, and three black spots at fork of $\mathrm{R}_{2+3}$, on basal part of $\mathrm{M}_{2}$ and at tip of $\mathrm{Cu}_{2}$. Male hypopygium with ventral clasper long, almost straight, tapered, and with many short spinules at tip; dorsal appendage slender and undulated. Female subgenital plate broad.

Pupa : - Body brown or dark brown, about 5-7 mm long, with many setae. Thoracic respiratory horn short, with a single row of close-set minute spiracular openings. Posterior margins of abdominal segments each with a row of distinct setae both dorsally and ventrally. Caudal end with a pair of strong thorn-like projections.

Larva : - Body about 8-10 mm long, brown in general colouration, with many distinct setae and well developed dorsal plates. Thoracic and first abdominal segment each with two dorsal plates and second to seven abdominal segment each with three dorsal plates. Respiratory tube, black, moderatory stout, conical.

The above brief descriptions are based on the free living immature stages and the parasitic materials are somewhat different in the following points: Both the larvae and pupae are smaller being about $6-7 \mathrm{~mm}$ and $4-6 \mathrm{~mm}$ long respectively and the body setae are far shorter. The smaller size of the immature forms are thought to be due to the abnormal parasitic life and the short setae are thought to be broken by the peristalsis of the intesine during the parasitic stage.

The life-history and morphology of this moth-fly have been studied by Efflatoun, H. C. (1921) and Zavattari, E. (1924). I have shown the larva and pupa of this moth-fly as an undetermined Telmatoscopus sp. in "Illustrated pocket book of insect larvae" (1951).

\section{Literature}

1) Dyar, H. G. (1926) : Three Psychodids from Glacier National Park. Insect. Inscit. Menstr., 14: 103-106.

2) Dyar, H. G. (1928) : American Psychodidae - II (Diptera). Proc. Ent. Soc. Wash., 30 (5): 87-89.

3) Eaton, A. E. (1894): A synopsis of British Psychodidae. Ent. Month. Mag., Ser. II, 5: 55-28. 
4) Efflatoun, H. C. (1921) : The life-history of Telmatoscopus meridionalis Eaton (Dipt.). Soc. Ent. Egypte, Bull., 1920 : 22-24.

5) Fullaway, D. T. (1907) : Immature stages of a Psychodid fly. Ent. News, 18: 386-389.

6) James, M. T. (1947) : The flies that cause myiasis in man. U. S. Dept. Agr., Misc. Publication, No. 632 .

7) Johannsen, D. A. (1934) : Aquatic Diptera, Part I. Nemocera, exclusive of Chironomidae and Ceratopogonidae. Cornell Univ., Agr. Exp. Stat., Memoir 164.

8) Matheson, R. (1950) : Medical Entomology. New York.

9) Okada, Jo K. (1927) : Un cas nouveau de myiase du tube digestif causé par la larve de $P_{s y-}$ choda sexpunctata Curt. Ann. Parasit., 5 (2) : 105-106.

10) Patton, W. S. \& Evans, A. M. (1929): Insects, ticks, mites and venomous animals of medical and veterinary importance. Croydon.

11) del Rosario, F. (1936): The American species of Psychoda (Diptera: Psychodidae). Philip pine Jour. Sci., $59: 85-148$.

12) del Rosario, F. (1936) : Phillipine Psychodidae (Dipt.), I. Psychodidae. Philippine Jour. Sci., $59: 455-569$.

13) Tokunaga, M. (1943) : Medical Entomology. Tokyo.

14) Tokunaga, M. (195i) : Illustrated pocket book of insect larvae. Tokyo.

15) Tonnoir, A. L. (1940): A synopsis of the British Psychodidae (Dipt.). with descriptions of new species. Trans. Soc. Brit. Ent., $7: 21-64$.

16) Williams, F. X. (1943) : Biological studies in Hawaiian water-living insects - Part III. Diptera or flies - C, Tipulidae and Psychodidae. Proc. Haw. Ent. Soc., 11 ( 3 ) : 323-338.

17) Zavattari, E. (1924) : Ricerche morfologiche ed etologiche sullo psicodide Telmatoscopus meridionalis Eaton. Redia 15 : 191-235. 